\title{
Folic Acid and Vitamin B12 Fortification of Flour: A Global Basic Food Security Requirement
}

\author{
Godfrey P. Oakley, Jr. MD, MSPM, ${ }^{1}$ \\ Theodore H Tulchinsky MD MPH ${ }^{2}$
}

\begin{abstract}
Folic acid is an essential water soluble B vitamin which has been used for decades in the prevention of folate deficiency anemia of pregnancy. In 1991, folic acid taken prior to the start of pregnancy was shown unequivocally to prevent spina bifida and anencephaly - two of the most serious and common birth (neural tube) defects. Soon governments recommended that women of reproductive age consume folic acid daily to prevent these birth defects. Because compliance was low and since more than half of pregnancies are unplanned, the United States Food and Drug Administration mandated in 1998 that all enriched flour be fortified with folic acid at a concentration estimated to give the average woman an intake of 100 micrograms of folic acid a day. Canada and Chile followed with similar requirements for folic acid fortification of wheat flour. Now there is mandatory fortification in more than 50 countries globally.

Where fortification has been implemented and studied, it has led to dramatic increases in serum folate concentrations, reduction in neural tube defects, folate deficiency anemia, as well as the reduction in homocysteine concentrations and stroke mortality with no known risk. Australia implemented mandatory folic acid fortification in 2009. To date, no country in Europe has implemented mandatory folic acid fortification of flour, although it has been recommended by the UK Food Safety Authority. This review discusses the vital importance of mandatory flour fortification with folic acid and vitamin B12, for public health food security and as a challenge to the New Public Health in Europe and globally.
\end{abstract}

Key Words: folic acid, vitamin B12, food fortification, micronutrients, birth defects, spina bifida, neural tube defects, anemia, homocysteine, stroke, nutrition

\footnotetext{
${ }^{1}$ Research Professor of Epidemiology, Rollins School of Public Health, Emory University, Atlanta, GA, USA.

${ }^{2}$ Braun School of Public Health, Hebrew University-Hadassah, Ein Karem, Jerusalem, Israel 91120.
}

Correspondence: Godfrey Oakley at email gpoakley@mindspring.com 


\section{INTRODUCTION}

Dr. Lucy Wills reported in 1931 that yeast extract/marmite could provide a remarkable cure for the "pernicious anemia of pregnancy" and "tropical anemia" among her patients at the Haffkine Institute, Parel, India, where she worked at the Maternal Mortality Inquiry, Indian Research Fund Association. ${ }^{1}$ These are the first observations of the use of folate to cure a folate deficiency human disease. Folic acid was synthesized in the 1940s and has been used by millions of pregnant women to prevent folate deficiency anemia associated with pregnancy. Folic acid combined with iron continues to be a program promoted by the World Health Organization (WHO) for women in the latter half of pregnancy in developing countries. Millions of other people took multivitamins containing folic acid to improve their health. Health workers used large doses of folic acid to cure folate deficiency anemia around the world. The role of folate in one-carbon metabolism was worked out and anti-folates became the mainstay of cancer treatment.

Sixty years after the Wills paper, Sir Nicholas Wald and colleagues at the United Kingdom's Medical Research Council demonstrated that spina bifida and anencephaly are folate deficiency diseases by reporting a randomized controlled trial proving that folic acid would prevent these important birth defects. This opened a new, important chapter in the ability of folic acid to prevent human disease. ${ }^{2}$ Although flour fortification was implemented in the United States in the early 1940s for thiamine, riboflavin, niacin and iron, the science of folate and B12 deficiency diseases had not advanced far enough for folic acid or vitamin B12 to be included in this original fortification. In the mid-1970s, the U.S. Food and Nutrition Board recommended adding folic acid to flour because of concern that older Americans were folate deficient, but the U.S. Food and Drug Administration (US FDA) did not mandate fortification at that time. The landmark paper by Wald and associates prompted policy discussions that led the US FDA to require, by January 1, 1998, that enriched grains have folic acid added at a concentration estimated to provide women of reproductive age 100 micrograms of folic acid a day. ${ }^{3,4}$ Marked increases in serum folate concentrations and reductions in spina bifida and anencephaly rates were observed as a result. ${ }^{5-8}$ This public health success story led Professor Irwin Rosenberg to write that this "...may be the most important science-driven intervention in

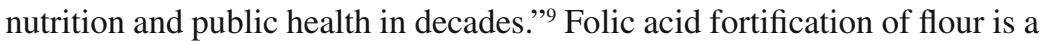
sterling example of the New Public Health.

The new and improved Haemophilus influenzae type b vaccine was also developed in the early 1990s. Within two years, developed countries, 
including those in Europe, rapidly implemented immunization programs that greatly improved child health by virtually eliminating invasive Haemophilus influenzae disease. It is surprising that, nearly 20 years after the scientific proof that folic acid prevents neural tube defects and more than 10 years since the countries in North America required folic acid fortification and demonstrated that such action prevents neural tube defects in the population, no country in Europe has required folic acid fortification. Not only would such a policy prevent neural tube defects in Europe, but it would also virtually eliminate folate deficiency anemia and lower serum homocysteine concentrations with the likelihood of preventing strokes with no known risks. ${ }^{10}$ The most puzzling public policy stance in Europe is taken by the Netherlands, which, rather than implement a folic acid fortification program that would prevent spina bifida, has chosen euthanasia for many with spina bifida.

A complete review of the folate/folic acid field is outside the scope of this review. The new edition of Lynn Bailey's "Folate in Health and Disease" which has just been published, is an up-to-date and comprehensive review of folate in health and disease. ${ }^{11} \mathrm{~A}$ chapter by Berry, Mulinare and Hamner in the book is a very well written and documented overview of the results of folic acid fortification. ${ }^{5}$ Two other new papers are also very good summaries of the issues of flour fortification-one concerns folic acid and the other vitamin B12. ${ }^{12,13}$ The World Health Organization (WHO) has also recently written guidelines reviewing food fortification to prevent micronutrient deficiencies, including those for folic acid. ${ }^{14}$

\section{FOLIC ACID PREVENTS BIRTH DEFECTS}

Spina bifida and anencephaly incidence rates vary by time, place and person, which has suggested to epidemiologists for many years that they were caused by a major environmental, rather than a genetic agent(s). ${ }^{15}$ Because poorer women had higher rates of spina bifida and anencephaly, the English pediatrician Richard Smithells thought that these birth defects might be nutritional diseases; he began to assemble evidence to support his idea in the 1960s. He and his colleagues performed metabolic testing and found evidence to suggest that folate metabolism was more common among post-partum women who had babies with birth defects than among those who had normal babies. ${ }^{16}$ Because of the necessity for folate in cell division, he was curious about whether or not these observations pointed to folate deficiency. In the late 1970s, he tried to conduct a randomized controlled trial that was not approved by three of four hospital research review boards; 
the result was a non-randomized study. Although his findings were striking - a 75 percent reduction in spina bifida and anencephaly recurrence in women treated with a multivitamin before and during the early weeks of pregnancy - inferences were constrained because the study was not randomized. ${ }^{17,18}$

Sir Nicholas Wald was able to convince the United Kingdom Medical Research Council (MRC) to provide resources for a proper randomized trial in recurrence prevention, and Hungarian pioneer Andrew Czeizel conducted a randomized controlled trial among women in the general population. The MRC study was a two-by-two design that permitted one to determine if it was folic acid alone or folic acid with other vitamins that Smithells used that prevented the birth defects. In the end, the study was stopped early because the folic acid arms showed that folic acid prevented 72 percent of the recurrence of birth defects and proved folate deficiency to be the primary cause. ${ }^{2}$ About nine months later, the Czeizel trial in Hungary was called off early because the test group given multivitamin containing 800 micrograms of folic acid had no cases of neural tube defects while the placebo control group had six cases. ${ }^{19}$

Two weeks after the publication of the MRC paper in The Lancet, the US Centers for Disease Control and Prevention (CDC) published recommendations that all women who had had a child with spina bifida or anencephaly births should consume 4000 micrograms of folic acid daily before and during early pregnancy to prevent the birth defects. ${ }^{20} \mathrm{~A}$ year later, the U.S. Public Health Service (CDC, FDA, National Institutes of Health, and others) published recommendations indicating that all women who could potentially become pregnant should consume 400 micrograms of folic acid daily to prevent the birth defects. ${ }^{21}$ Discussions then began on how to maximize the prevention of neural tube defects by greatly increasing the proportion of women who consumed the recommended 400 micrograms of folic acid a day.

Because at least half of pregnancies are unplanned, a policy that seeks only to have women begin taking a supplement when they are planning a pregnancy will fail at least half the time. The supplement would be quite effective for those who took them, but there would of course be no prevention among the women who did not take the supplement. It was assumed at the time that recommendations geared toward all women of reproductive age to consume folic acid daily might have high compliance among the well educated population, but would be ignored by many, even the majority. It has subsequently been shown that government recommendations alone, including those in Europe, fail to improve 
consumption. ${ }^{22}$ Thus if children are to have the full benefit of folic acid in preventing birth defects, there needs to be mandatory folic acid fortification in a commonly consumed food. Milk and orange juice were considered as potential vehicles for the substance, but flour was finally chosen because it is so widely and consistently consumed.

There was a very thorough policy discussion about whether or not to fortify and at what concentration. The FDA finally decided upon a concentration that was projected to increase the consumption of folic acid by women of reproductive age by 100 micrograms, a concentration resulting in the complete prevention of folic acid-preventable spina bifida and safe for population wide use. In the 1960s, the FDA would never have approved a polio vaccine with only one of the three polio strains that cause polio, because there would be unnecessary cases of polio. This low concentration of folic acid was selected because of an error in the modeling by the FDA. The FDA decided based on a risk hypothesis stating that the fortification concentration should be set so that an 18-year-old male consuming a multivitamin with 400 micrograms of folic acid, and eating food made with fortified flour, would not consume more than 1000 micrograms of total folate daily - the sum of synthetic folic acid and the natural folate in food. They were concerned that folic acid could mask the anemia of B12 deficiency, and thereby potentially prevent diagnosis and treatment of this condition. The biochemistry is such, however, that folate contained in food cannot cure the anemia of B12 deficiency. The cause of the anemia in B12 deficiency is the biochemical block caused by B12 deficiency in the metabolism of 5-methyltetrahydrofolate to tetrahydrofolate.

Several years later, the Institute of Medicine (IOM) report corrected this mistake by setting the upper tolerable level as 1000 micrograms of synthetic folic acid. Had the FDA modeling not been erroneous, the fortification level in the United States would have been projected to give women at least 200 micrograms a day. In March 1996, the FDA issued regulations requiring enriched grains to have 140 micrograms of folic acid per 100 grams (1.4 parts per million) by January $1,1998 .{ }^{3}$ Canada required a similar folic acid fortification of flour several months later. ${ }^{6}$

Folic acid fortification has been a huge success. Those who were in favor of higher fortification levels have been pleasantly surprised that the prevention of birth defects is greater than initially expected. Those who were concerned about the safety of fortification were also reassured. To this day, no validated risk has been found nor has any litigation been initiated, even after hundreds of millions of North Americans have been consuming flour fortified with folic acid for more than a decade. 


\section{BLOOD FOLATES ARE INCREASED AND FOLATE DEFICIENCY ANEMIA VIRTUALLY ELIMINATED}

The Berry chapter in the Bailey book describes the remarkable increase in serum and red blood cell (RBC) folates that occurred after fortification. ${ }^{5}$ The shift upwards of the distributions of serum and RBC folates are sufficient to virtually eliminate folate deficiency anemia. A recent publication from a Canadian health provider suggested that folate deficiency anemia was so rare that there should be no routine serum folate testing in the presence of anemia as it is an unnecessary use of resources. ${ }^{23}$

\section{FOLIC ACID FORTIFICATION PREVENTS SPINA BIFIDA AND ANENCEPHALY}

It is not known for certain the extent to which spina bifida can be prevented. It is likely to vary depending on the pre-fortification baseline rates were for spina bifida and anencephaly. The U.S. Public Health Service (USPHS) recommendations were originally based on the United Kingdom MRC study, which had shown a 70 percent reduction, and not the Czeizel study which indicated a 100 percent prevention. ${ }^{2,19}$ Conservatively, the USPHS estimated that about half of spina bifida and anencephaly cases were preventable. ${ }^{21}$ Studies from the US and Canada show 25 to 50 percent reductions. ${ }^{6,7} \mathrm{~A}$ large community trial in China, performed in both high and low risk areas, showed that 400 micrograms of folic acid reduced incidence rates by 90 percent in the high risk areas and by about 40 percent in the low risk areas. ${ }^{24}$ Interestingly enough, rates in both areas approached 5 per 10,000 pregnancies.

The fact that several provinces in Canada still have spina bifida and anencephaly rates of more than 1 per 1,000 live births suggests that prevention could be augmented by increasing the concentration of folic acid fortificant. Doubling the concentration and monitoring the rates could indicate what amount of folic acid is necessary to prevent all folic acidpreventable birth defects. Current levels of fortification may not be sufficient to achieve maximum potential preventive effects, and assuring complete prevention probably requires increasing the concentration of folic acid in flour. 


\section{FOLIC ACID FORTIFICATION PROVIDES ALMOST EVERYONE IN THE POPULATION WITH 100 MICROGRAMS OF FOLIC ACID}

Berry and colleagues were curious about those who had blood folates in the upper quintile, because of reports of poor cognitive performance among people with upper folate quintiles and low serum B12 concentrations. ${ }^{25}$ In contrast, those with normal B12 concentrations and folates in the upper quintile had a 50 percent reduction in cognitive problems. Berry and colleagues showed that, remarkably, the consumption of synthetic folic acid from mandatory fortification was a near constant 100 micrograms of serum folate across the whole distribution of population. ${ }^{26}$ They showed that those in the upper quintile with regards to serum folate reach that level by voluntarily consuming vitamin supplements or breakfast cereals fortified with folic acid. This observation is very important for those considering mandatory folic acid fortification. The current evidence suggests that an extra 100 micrograms of folic acid from fortification is safe for the population, so that safety concerns cannot be professionally used as an argument against fortification.

However, political blocking of mandatory fortification of flour with folic acid continues to occur. For example, during the summer of 2009, the Prime Minister of New Zealand blocked bread fortification arguing safety reasons. Long delayed in Australia, fortunately, folic acid fortification was implemented on schedule in September of 2009. In the UK, the recommendation of the Food Standards Agency (FSA) of 2007 was turned back by the Chief Medical Officer for further review of the evidence, then resubmitted in 2009, and now awaits ministerial decision.

\section{FOLIC ACID FORTIFICATION IS SAFE}

Often the policy discussions on folic acid fortification bring up hypotheses of risk based primarily on conjecture or modest data. Recent hypotheses of risk are from studies that used high doses of folic acid-usually 1000 micrograms a day or more. No risks were evidenced even from these high exposures. ${ }^{12}$ Moreover, even if these high doses were harmful, the process of folic acid fortification, in itself, would be safe, because it could never lead to such intake levels. As stated earlier, folic acid fortification leads to rather uniform consumption of about 100 micrograms per day, depending upon the level of folic acid fortificant added to the flour. ${ }^{26}$ The data are clear, indicating that there is no known risk from ingesting an extra 100 micrograms of folic acid a day. 


\section{FOLATE FOOD SECURITY REMAINS A PROBLEM IN ALL OF EUROPE}

Folate security remains a problem in all of Europe and many other countries around the world. Bell and Oakley ${ }^{27}$ recently reviewed progress on flour fortification and prevention. Figure 1 shows that more than 50 countries, including most of those in the Americas, have mandated folic acid fortification, but that no country in Europe has yet required it. Australia initiated mandatory folic acid fortification in 2009. Bell and Oakley estimated that only 10 percent of the preventable spina bifida is actually being prevented. The total global prevention of these birth defects will require mandatory folic acid fortification of flour in Europe.

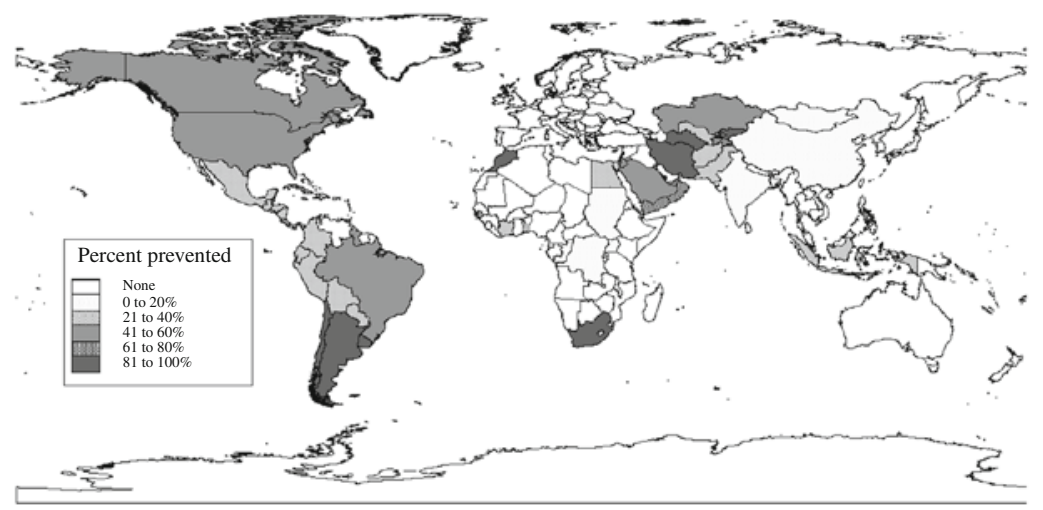

Fig. 1. Folic Acid Preventable Spina Bifida And Anencephaly, 2008.

Source: Source: Bell KN, Oakley GP. Update on Prevention of Folic Acid-Preventable Spina Bifida and Anencephaly. Birth Defects Res (Part A). 2009;85:102-7.

\section{VITAMIN B12}

Pernicious anemia is a severe and fatal disease if not treated with vitamin B12. One of the great medical success stories is the identification in the 1930s and 1940s that this disease was caused by a severe deficiency of vitamin B12 brought on by an auto-immune disease that destroys the cells in the stomach which make a protein — intrinsic factor-that catalyzes the absorption of vitamin B12. Furthermore, it was shown that the disease could be cured by treatment with liver extract. Later therapeutic forms of B12 that could be given by injection were produced. Now this disease can 
be cured and prevented with very large doses of oral vitamin B12. In recent years there has been evidence that many older people have a modestly low vitamin B12 concentration that is not caused by pernicious anemia. Both forms of vitamin B12 deficiency respond to vitamin B12. Folic acid will neither prevent nor cure these vitamin B12 conditions, but will also not make these worse. These vitamin B12 deficiency conditions simply require enough vitamin B12.

\section{MANDATORY FORTIFICATION OF FLOUR WITH VITAMIN B12 LOW DOSE VITAMIN B12 DEFICIENCY IS WIDESPREAD}

In the late 1990s, the Framingham studies showed that mild B12 deficiency was very prevalent, with or without increased homocysteine or methyl malonic acid concentrations. Studies also showed that the prevalence, regardless of how the deficiency was defined, was reduced by 70 percent among those who consumed vitamin pills that contained a median of six micrograms of vitamin B12. ${ }^{28}$ It is usually thought that this B12 insufficiency is due to reduced gastric acid secretion, thereby preventing absorption of food-bound vitamin B12, even in the presence of adequate intrinsic factor. Studies from Europe show similar findings. ${ }^{29}$

It is not known whether this mild insufficiency of serum B12 concentrations causes disease. Nevertheless, based on this evidence, in 1998 the United States Institute of Medicine recommended that those aged 50 and older should consume 2.4 micrograms of vitamin B12 daily from vitamin supplements or foods containing synthetic vitamin B12.30

Longstanding experience in the United States, Canada and other countries, most recently with folic acid fortification, has shown that flour fortification is a very effective way to get a B vitamin to the whole population in a nearly uniform dose. Studies in Europe have shown that the deficiency exists and that adding a modest amount of vitamin B12 to flour will cure the insufficiency. ${ }^{29}$ Until mandatory B12 fortification is implemented in Europe, the prevalence of B12 insufficiency will continue. This form of vitamin B12 deficiency would likely disappear if there was mandatory fortification of flour in Europe.

\section{SUMMARY AND CONCLUSIONS}

Longstanding experience of fortifying flour with iron and several water soluble B group vitamins in the US, Canada and many other countries, has 
shown success in preventing micronutrient deficiency conditions, most recently in the very cost-effective prevention of spina bifida, anencephaly, and folate deficiency anemia. Folic acid fortification has led to reductions in primary stroke possibly due to elevated homocysteine levels. More than 50 countries have implemented mandatory folic acid fortification, including the US (1998) and most recently, Australia (September 2009). No known risks have been associated with folic acid fortification which has been in place for more than a decade, reaching hundreds of millions of North Americans. Vitamin B12 deficiency is also widespread, and can be prevented to a great extent by adding vitamin B12 to flour.

No European country has as yet implemented mandatory folic acid or B12 fortification, so that Europeans are being exposed to this unnecessary food insecurity. In the best interest of public health, all countries in Europe and around the world should move quickly to require folic acid and B12 flour fortification.

In this review, we have discussed the vital importance of mandatory folic acid and vitamin B12 fortification of flour for public health food security. We recommend wide public education of the benefits of folic acid along with promotion of regular use of folic acid supplements for women capable of pregnancy, adoption of universal mandatory fortification of flour with folic acid and vitamin B12, and promotion of folate rich foods in regular diets. We see this as a crucial challenge to the New Public Health in Europe and globally.

Contributors: Godfrey Oakley led and developed this article; Theodore Tulchinsky made substantive suggestions and revisions in subsequent versions.

Disclaimer: GPO is a co-inventor (while at CDC; compensation, if any, will be under the regulations of $\mathrm{CDC}$ ) of a patent that covers adding folic acid to contraceptive pills. He has been a paid consultant to Ortho McNeil/Johnson and Johnson on this issue and may be in the future. He has not done paid consulting on this issue over the last 2 years. THT has taught and published on policy issues in prevention of birth defects and in food fortification.

\section{REFERENCES}

1. Wills L. Treatment of «pernicious anaemia of pregnancy» and «tropical anaemia» with special reference to yeast extract as a curative agent. BMJ. 1931;1:1059-64.

2. MRC Vitamin Study Research Group. Prevention of neural tube defects: results of the Medical Research Council Vitamin Study. MRC Vitamin Study Research Group. Lancet. 1991;338:131-7. 
3. Food and Drug Administration. Food standards: amendment of standards of identity for enriched grain products to require addition of folic acid. Fed Regist. 1996;61:8781-807.

4. Food and Drug Administration. Food labelling: health claims and label statements; folate and neural tube defects. Fed Regist. 1996;61:8752-81.

5. Berry RJ, Mulinare J, Hamner HC. Folic acid fortification: neural tube defect risk reduction - a global perspective. In: Bailey LB, editor. Folate in health and disease. Boca Raton, (FL): CRC Press; 2010.

6. De Wals P, Tairou F, Van Allen MI, Uh SH, Lowry RB, Sibbald B, et al. Reduction in neural tube defects after folic acid fortification in Canada. N Engl J Med. 2007;357:135-42.

7. Honein MA, Paulozzi LJ, Mathews TJ, Erickson JD, Wong LY. Impact of folic acid fortification of the US food supply on the occurrence of neural tube defects. JAMA. 2001;285:2981-6.

8. Pfeiffer CM, Caudill SP, Gunter EW, Osterloh J, Sampson EJ. Biochemical indicators of B vitamin status in the US population after folic acid fortification: results from the National Health and Nutrition Examination Survey 19992000 (and supplemental tables). Am J Clin Nutr. 2005;82:442-50; S1-S4.

9. Rosenberg IH. Science-based micronutrient fortification: which nutrients, how much, and how to know? Am J Clin Nutr. 2005;82:279-80.

10. Yang Q, Botto LD, Erickson JD, Berry RJ, Sambell C, Johansen H, Friedman JM. Improvement in stroke mortality in Canada and the United States, 1990 to 2002. Circulation 2006;113:1335-43.

11. Bailey LB, editor. Folate in health and disease. Second ed. Boca Raton: CRC Press; 2010.

12. Folic Acid Working Group: Berry RJ, Bailey L, Bower C. Fortification of flour with folic acid. Food Nutr Bull. 2010;31:S22-S35.

13. Allen LH, Rosenberg IH, Oakley GP, Omenn GS. Considering the case for vitamin B12 fortification. Food Nutr Bull. 2010;31:S36-S46.

14. World Health Organization and Food and Agriculture Organization. Guidelines on Food Fortification with Micronutrients. Geneva: World Health Organization and Food and Agriculture Organization of the United Nations; 2006.

15. Leck I. Causation of neural tube defects: clues from epidemiology. Br Med Bull. 1974;30:158-63.

16. Hibbard ED, Smithells RW. Folic acid metabolism and human embryopathy. Lancet. 1965;285:1254.

17. Smithells RW, Sheppard S, Schorah CJ, Seller MJ, Nevin NC, Harris R, et al. Possible prevention of neural-tube defects by periconceptional vitamin supplementation. Lancet. 1980;315:339-40.

18. Oakley GP, Adams MJ, James LM, Smithells RW, Seller MJ, Fielding DW, et al. Vitamins and neural tube defects. Lancet. 1983;322:798-9.

19. Czeizel AE, Dudas I. Prevention of the first occurrence of neural-tube defects by periconceptional vitamin supplementation. N Engl J Med. 1992;327:1832-5. 
20. Centers for Disease Control and Prevention. Use of folic acid for prevention of spina bifida and other neural tube defects - 1983-1991. MMWR Morb Mortal Wkly Rep. 1991;40:513-6.

21. Centers for Disease Control and Prevention. Recommendations for the use of folic acid to reduce the number of cases of spina bifida and other neural tube defects. MMWR Morb Mortal Wkly Rep. 1992;41:1-7.

22. Botto LD, Lisi A, Robert-Gnansia E, Erickson JD, Vollset SE, Mastroiacovo P et al. International retrospective cohort study of neural tube defects in relation to folic acid recommendations: are the recommendations working? BMJ. 2005;330:571.

23. Shojania AM, von Kuster K. Ordering folate assays is no longer justified for investigation of anemias, in folic acid fortified countries. BMC Research Notes 2010;3.

24. Berry RJ, Li Z, Erickson JD, Li S, Moore CA, Wang H, et al. Prevention of neural-tube defects with folic acid in China. China-U.S. collaborative project for neural tube defect prevention [corrected; erratum published 341:1864]. N Engl J Med. 1999;341:1485-90.

25. Morris MS, Jacques PF, Rosenberg IH, Selhub J. Folate and vitamin B-12 status in relation to anemia, macrocytosis, and cognitive impairment in older Americans in the age of folic acid fortification. Am J Clin Nutr. 2007;85:193200.

26. Yang Q, Cogswell ME, Hamner HC, Carriquiry A, Bailey LB, Pfeiffer CM, et al. Folic acid source, usual intake, and folate and vitamin B-12 status in US adults: National Health and Nutrition Examination Survey (NHANES) 20032006. Am J Clin Nutr. 2010;91:64-72.

27. Bell, KN and Oakley, GP, Jr. Update on prevention of folic acid-preventable spina bifida and anencephaly. Birth Defects Res Part A 2009;85:102-7.

28. Lindenbaum J, Rosenberg IH, Wilson PW, Stabler SP, Allen RH. Prevalence of cobalamin deficiency in the Framingham elderly population. Am J Clin Nutr.1994;60:2-11.

29. Winkels RM, Brouwer IA, Clarke R, Katan MB, Verhoef P. Bread cofortified with folic acid and vitamin B-12 improves folate and vitamin B-12 status of health older people: a randomized controlled trial. Am J Clin Nutr. 2008;88:348-55.

30. Institute of Medicine. Dietary reference intake: thiamin, riboflavin, niacin, vitamin B6, folate, $\mathrm{p}$ antothenic acid, biotin, and choline. Institute of Medicine: Washington (DC): National Academy Press 1998. 